J. Perinat. Med. 14 (1986) 181

\title{
Analysis of cerebroarterial Doppler flow velocity waveforms in new- born infants: towards an index of cerebrovascular resistance
}

\author{
Gorm Greisen
}

Department of Neonatology, Rigshospitalet, Copenhagen, Denmark

\section{Introduction}

Doppler ultrasound is attractive for the study of cerebral hemodynamics in newborn infants as radiation exposure limits the use of tracer clearance techniques. A number of clinical studies have been published during the last few years as reviewed by VoLPE [17].

A pulsatility index ((systolic flow - diastolic flow)/systolic flow) has been used most often as proposed by BADA et al. [1]. This index was developed by POURCELOT [13] (and was actually labelled 'index de résistance'; this term will be used in this report) to estimate cerebrovascular resistance in adults, when cerebrovascular compliance and changes in aortic blood pressure wave could be ignored. The resistance index has not been validated against a standard calculation of cerebrovascular resistance, and concern about its use in newborn infants has been raised [3].

Determination of cerebral blood flow (in terms of volume flow per $100 \mathrm{~g}$ brain weight) by Doppler ultrasound faces a number of difficulties. In brief these are: 1) to obtain a signal from a single straight non-dividing artery; 2) to get an equal representation of the flow profile in the recorded frequency spectrum; 3 ) to remove frequency shifts due to the slowly moving vessel wall; 4) to determine the weighted mean frequency shift; 5) to determine the time averaged mean frequency shift; 6) to determine the angle between the vessel and the sound beam; and 7) to determine the arterial cross-sectional area in relationship to the mass of brain tissue supplied by the artery. Validation against standard measures of volume flow, relevant for the study of newborns, have showed fairly encouraging results. The in vitro precision is in the order of $\pm 5 \%$ [11], in human adults $\pm 10 \%$ [14], in experimental newborn animals $\pm 30 \%[2,8]$ and in newborn infants the precision was $\pm 35 \%$ [7]. This level of imprecision gives room for considerable systematic errors. Even in the best of situations, in short term studies of trends within individual infants, with constant transducer position, dynamic changes in arterial diameter may give rise to significant errors.

The purpose of the present report is to point out the ambiguities in the interpretation of a clinical research application of Doppler ultrasound, estimating mean flow velocity and the resistance index, to analyze possible sources of bias and to propose a principle for improving the estimation of cerebrovascular resistance.

\section{Methods}

\subsection{Clinical study}

The infant studied was born at term with a birth weight of $2435 \mathrm{~g}$ and was admitted because of severe birth asphyxia (there was no heart action for the first 8 minutes of life, and $\mathrm{pH}$ in umbilical arterial blood was 6.89). The recording was 
carried out at 20 hours of age while the infant was on mechanical ventilation. Transcutaneous $\mathrm{PO} 2$ and $\mathrm{PCO} 2$ values were within normal ranges during the recording period, the phenobarbitone level was $33 \mathrm{mg} / \mathrm{l}$. Heart rate (HR) and mean arterial blood pressure (MABP) were recorded from the thoracic aorta, and the mean flow velocity (MFV) from the anterior cerebral artery was recorded by Doppler ultrasound (ALFRED, Vingmed, Norway hand held $5 \mathrm{MHz}$ transducer in range gated mode [7]). The angle between the anterior cerebral artery, as it curves anteriorly of the corpus callosum and the sound was assumed to be so close to zero as to allow the use of MFV without correction for angle of insonation. The resistance index (RI) was calculated from interupted tracings of the maximal frequency shift signal. Another index of cerebro-vascular resistance (CVR) was calculated as CVR $=\mathrm{MABP} / \mathrm{MFV}$ $\times 10$.

\subsection{Hemodynamic model}

A simple, conventional electrical analogy of a hemodynamic system [16] was adapted to model the systemic circulation of the newborn (figure 1). In this model, all parts of the circulation not supplying the brain was called "peripheral" and characterized by a common resistance, R2, and a common arterial compliance, C2. The peripheral resistance thus denoted the common resistance to blood flow through the truncus, extremities and extracranial tissues. The cerebral circulation was represented by $\mathrm{R} 1$ and $\mathrm{C} 1$ as an aggregate coupled in parallel to the peripheral aggregate. The compliance of the aorta and arteries proximal to the site of Doppler ultrasound measurement was represented as a third capacitance, C3, and the arterial ductus by a third resistance, R3, both of which were coupled in parallel to the cerebral and peripheral aggregates. Finally, impedances to the arterial blood flow to the brain and the periphery were introduced (Ra1, L1 and Ra2, L2 respectively).

The voltage on $\mathrm{C} 3$ represented central arterial pressure while cerebral blood flow velocity was represented by the current through L1 and Ra1.

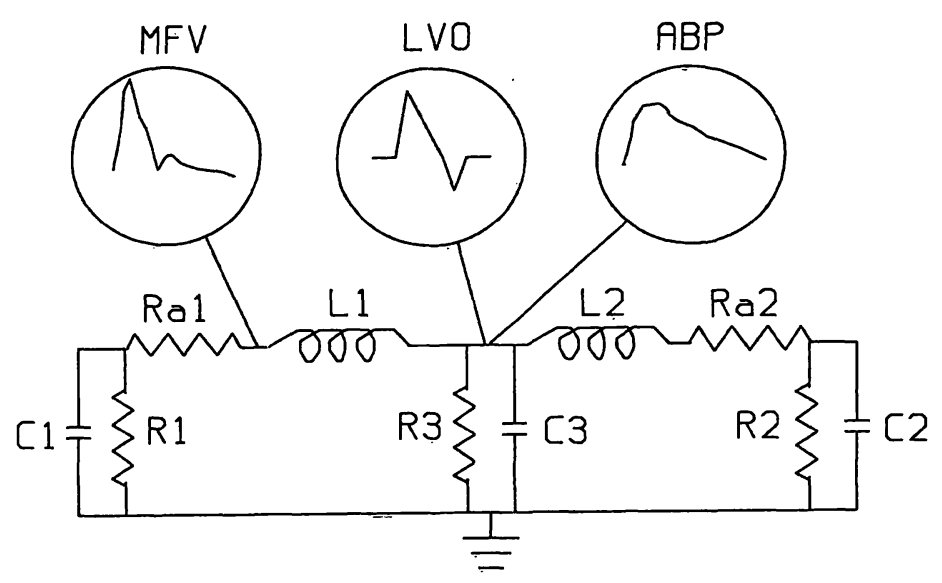

Figure 1. An electrical model of the systemic arterial system of the newborn.

R1, R2, R3: cerebrovascular, peripheral and ductal resistances

C1, C2, C3: cerebrovascular, peripheral and aortic compliances

L1, L2: inertances to cerebral and peripheral blood flow

Ra1, Ra2: arterial resistances to blood flow in cerebral and peripheral arterial trees.

The inserts show the impulse used to simulate left ventricular outflow, the resulting voltage in C3 (aortic blood pressure waveform) and the current through $\mathrm{L} 1$ and $\mathrm{Ra} 1$ (cerebral blood flow velocity waveform).

The model was simulated on a digital computer by calculating the six currents and the resulting voltages in 200 steps per cardiac cycle.

The parameter values of the basic state of the model were chosen as follows: left ventricular output (LVO, figure 1: insert) was generated to give a fair resemblance to experimental LVO curves [16]. The cerebrovascular resistance was set to 4 times the aggregate peripheral resistance whereas the ductal resistance was set to infinity to model a hemodynamic state with $15-20 \%$ of LVO going to the brain, a closed arterial ductus and an arterial pulse amplitude of $40 \%$ of systolic blood pressure. The values of the arterial impedances (Ra1, L1 and Ra2, L2) and compliances (C1 and C2) were chosen to model similar mean flow velocities in cerebral and peripheral arterial beds, similar pulse wave velocities of $4 \mathrm{~m} / \mathrm{sec}$, and mean lengths of the arterial systems of 10 and $20 \mathrm{~cm}$, respectively. The resulting cerebral blood flow velocity waveform and central blood pressure waveform were acceptable (figure 1: inserts). 
The RI was calculated from the cerebral blood flow velocity curve as (systolic flow - diastolic flow)/systolic flow. The RI of the basic state of the model was 0.74 . A pulsatility index ratio, PIR was calulated as an alternative index of cerebrovascular resistance as the ratio of (systolic flow - diastolic flow)/mean flow to (systolic pressure - diastolic pressure)/mean pressure. The PIR of the basic state of the model was 3.16.

The model parameters were increased by $10 \%$, one at a time, to estimate the sensitivity of RI and PIR. The cerebral blood flow velocity waveform and the blood pressure waveform were simulated and the resulting RI and PIR were compared to those of the basic state of the model.

\section{Results}

The recording in figure 2 shows two major, spontaneous rises in HR and MAPB; during the first episode the infant turned pale, during the second brief twichings of the hands were observed (EEG recorded 12 hours later showed focal paroxystic activity of $2-3$ min duration). The changes in MFV corresponded closely to those in MABP, while RI decreased during the

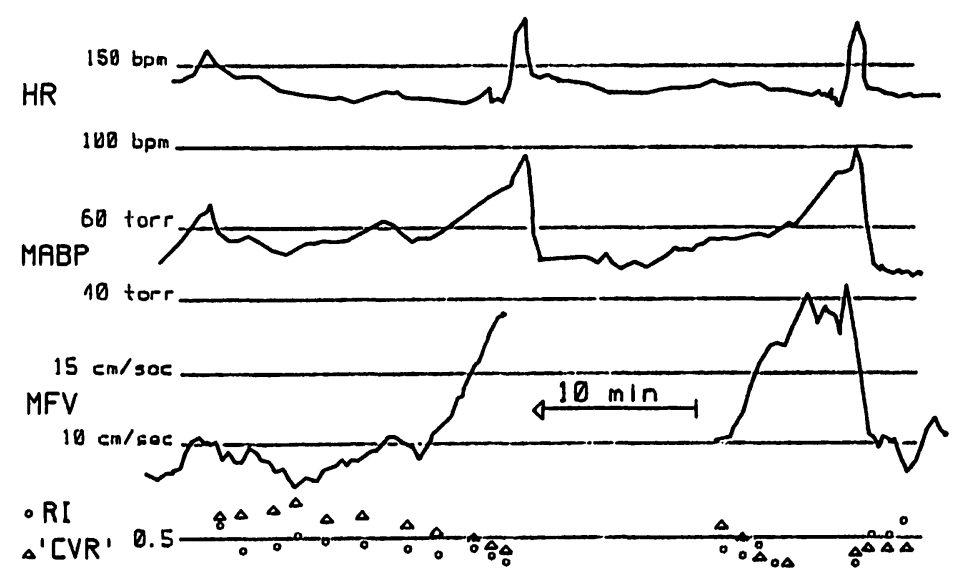

Figure 2. Recording of heart rate (HR), mean aortic blood pressure (MABP) and mean blood flow velocity (MFV), recorded from the anterior cerebral artery by Doppler ultrasound. Resistance index (RI) and "cerebrovascular resistance" (CVR) was calculated intermittently. The infant studied was severely asphyxiated and the two episodes of increased MABP was caused by epileptic seizures.
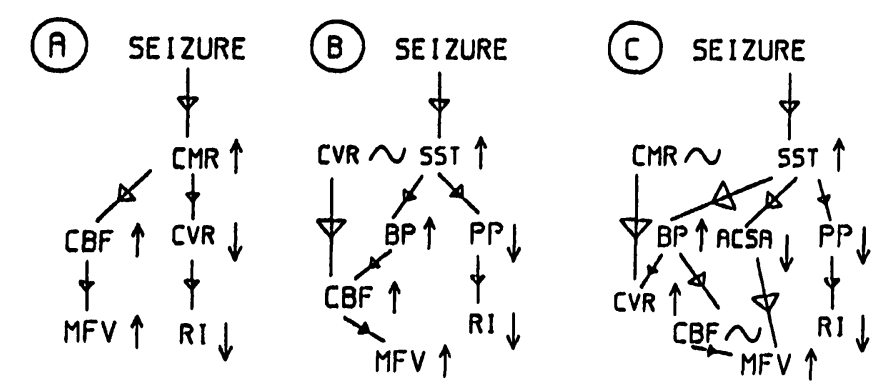

nETheOLISM-PLON

COUPLINE PRESLNT

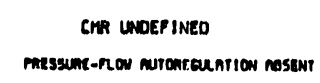

CAR UNCHANGED

neTneo. ISH-COULLING PRESENT

PRESSURE-FLOU RUTOREGULATION PRESENT

Figure 3. Three alternative interpretations of the changes in mean blood flow velocity (MFV), resistance index (RI), mean aortic blood pressure (MABP) illustrated in figure 2. Changes in ccrebral metabolic rate (CMR), cerebral blood flow (CBF), sympathetic system tone (SST), pulse pressure (PP) and arterial cross-sectional area (ACSA) werc hypothesised. In the diagrammes, relationships between two variables are indicated by arrows $(\longrightarrow$ ). Increase or decreases in variables by arrows, up $(\uparrow)$ and down $(\downarrow)$, respectively; whereas variables remaining unchanged arc indicated by $(\sim)$.

two episodes and corresponded well to the calculated "CVR". These changes could be interpreted in 3 different, mutually contradictive ways (figure 3 ) in terms of change in cerebral metabolic rate and presence of metabolism-flow coupling and pressure-flow autoregulation.

The computer simulated hemodynamic model supported that $\mathrm{RI}$ truly reflects changes in cerebrovascular resistance (table 1). A doubling of cerebrovascular resistance resulted in an increase of the RI about $20 \%$. But PI was as sensitive to other parameters as to cerebrovascular resistance. Most remarkable, changes in the compliance of cerebral arteries and the aorta influenced RI very significantly. Decrease in the compliance of cerebral arteries may follow increase in vasomotor tone, increase in arterial blood pressure and perhaps increase in intracranial pressure. Increase in blood pressure would decrease the compliance of the aorta as well, partly compensating the effect on RI. Increase in systolic time fraction was equally important and accompanies increased heart rates. Patency of the arterial ductus with a leftto-right shunt of $30 \%$ of LVO increased RI by $15 \%$. 
Table 1. Sensititivy of the resistance index, RI and pulsatitlity index ratio, PIR to changes of 7 parameters in a hemodynamic model of systemic arterial circulation.

\begin{tabular}{lll}
\hline Parameter & \multicolumn{2}{l}{ Partial derivatives } \\
\cline { 2 - 3 } & RI & PIR \\
\hline Cerebrovascular resistance & +0.20 & +0.82 \\
Peripheral resistance & -0.32 & +0.05 \\
Cerebroarterial compliance & +0.16 & +0.41 \\
Central compliance & -0.22 & -0.16 \\
Peripheral complicance & -0.09 & -0.12 \\
Heart rate & -0.09 & +0.54 \\
Systolic time fraction & -0.27 & -0.28 \\
\hline Patent arterial ductus & +0.15 & -0.03 \\
(30\% of left ventricular output) & & \\
\hline
\end{tabular}

The partial derivatives were obtained by simulating arterial blood pressure and cerebral blood flow velocity waveforms with each parameter value increased by $10 \%$ in turn. The partial derivatives were calculated as the difference of the resulting RI and PIR from those of the basic state of the model multiplied by 10 .

The pulsatility index ratio, PIR was more sensitive to changes in cerebrovascular resistance; PIR increased by $80 \%$. PIR was only little affected by changes in peripheral resistance, patent arterial ductus and central compliance. This was expected as PIR is corrected for the influence of the arterial pulse pressure. Heart rate affected PIR considerably, perhaps the effect would be partly compensated by the influence of systolic time fraction. Also, PIR was as sensitive to changes in cerebroarterial compliance as RI.

\section{Discussion}

Increased blood pressure during neonatal seizures was first decribed by Lou and FRIISHANSEN [9]. It is highly likely that this blood pressure increase is due to sympathetic activation. The effect of sympathetic discharge on cerebral hemodynamics is complex [6]. Apart from the blood pressure increase and pulse pressure decrease, cerebral arteries contract as well. Extracranial and pial arteries contract more than intracerebral arteries and anterior and middle cerebral arteries more than postierior cerebral and basilar arteries. The end-result is a slight decrease in global cerebral blood flow and a redistribution of flow from frontal to rostral parts of the brain. CBF in the case of seizures is further influenced by the size of the epileptic focus and possible secondary activation mediated by intracerebral cathecholaminergic pathways [6].

Recently, Pearlman and Volpe [12] have reported decreased $\mathrm{RI}$ and increased diastolic flow velocity (suggesting increased MFV), as well as increased blood pressure and intracranial pressure in 12 newborn infants during seizures. This was interpreted as reflecting increases in cerebral metabolic rate and cerebral blood flow and a decrease in cerebro-vascular resistance. The data and analysis presented here suggests that this interpretation is not definitive, although supported by changes in MFV as well as RI. The statistical significance achieved by the study of 12 infants does not remove the ambiguity of interpretation.

The ambiguity pointed out here in the case of seizures may be generalized to the use of MFV and RI during all forms of spontaneous blood pressure changes possibly involving changes in sympathetic activity. This point is important since loss of pressure-flow autoregulation has been suggested to be a crucial factor in the pathogenesis of intracranial hemorrhage. in newborn infants [10], and it is tempting to use Doppler ultrasound to document the presence or absence of such autoregulation. The requirement would be either to control for changes in cerebroarterial cross sectional area or to improve the index of cerebrovascular resistance.

The hemodynamic model presented here represents a great simplification of the arterial system. Fitting the resulting waveforms to experimental data was not attempted, but it is obvious that the dicrotic notch in the cerebral blood flow velocity waveform is more marked than what is seen experimentally. Even elaborate models may fail to fit experimental waveforms precisely [4]. Furthermore, only the sensitivity of RI and PIR to small and isolated changes 
in model parameters was analyzed. In practice such changes may be larger and occur in combination. The results should be regarded as indications only, but probably do give useful indications of likely sources of bias in the estimation of cerebrovascular resistance. The model analysis supported the suspicion in interpreting RI during seizures. Apart from the effect on pulse pressure, heart rate and thus systolic time fraction as well as cerebrovascular compliance was likely be changed, all to result in a decreased RI.

Correction for pulse pressure, as done in the calculation of PIR, appears to remove some of the problems in estimating cerebrovascular resistance. A similar approach, using the pulsatility of the flow velocity waveform from the descending aorta in the place of aortic pulse pressure has recently been reported [5]. A more complete analysis of flow velocity waveforms by LAPLACE transforms has allowed change in distal resistance to be separated from change in distal compliance in lower limb of human adults [15]. We have applied this approach to cerebroarterial waveforms obtained in newborn infants, but found the frequency bandwidth of the flow waveform as well as the pressure waveform insufficient.

In conclusion, even the combination of mean flow velocity and pulsatility index does not reliably decribe cerebral blood flow or resistance when the sympathetic system is activated. When the results fit the expectations, as in the presented case, one could say

\section{'that may be fine in practice}

but don't you see, it doesn't work out in theory'

A pulsatility index ratio, correcting for aortic pulse pressure may improve reliability but would require validation of its own.

\section{Summary}

Doppler ultrasound has been used extensively to study cerebral hemodynamics in the human newborn. This report presents a continuous recording in an infant with epileptic seizures. Heart rate, mean aortic blood pressure and mean flow velocity, obtained from the anterior cerebral artery by Doppler ultrasound, all increased markedly during the seizures. The Poucelot index was calculated from the cerebral blood flow velocity waveform and is supposed to reflect cerebrovascular resistance. This index decreased. Three mutually contradictive interpretations were possible in terms of cerebral metabolic rate, cerebral blood flow, metabolism-flow coupling and pressure-flow autoregulation. Sympathetic activation and its effects on cerebral hemodynamics is discussed. It is pointed out that the competence of the pressure-flow autoregulation may not be studied reliably during changes in blood pressure associated with altered sympathetic activity. An electrical model of the systemic arterial system is presented and used to demonstrate that the resistance index is likely to be severely affected by changes in cerebroarterial compliance, peripheral resistance, duration of systole as a fraction of heart cycle and patency of the arterial ductus. A pulsatility index ratio, which is corrected for arterial pulse pressure, is suggested to avoid some of these errors.

Keywords: Cerebral hemodynamics, Doppler ultrasound, hemodynamic model, newborn infant, seizure, sympathetic activation.

\section{Zusammenfassung}

Aufnahmen von Flow-Kurven in Zerebralarterien mit der Dopplersonographie und deren Analyse zwecks Erstellung eines zerebrovaskulären Widerstandsindex

Die zerebrale Hämodynamik beim Neugeborenen wurde mit der Dopplersonographie extensiv untersucht. In der vorliegenden Arbeit berichten wir über eine kontinuierliche Aufzeichnung bei einem Kind mit epileptischen Anfällen. Sowohl die Herzfrequenz wie auch der mittlere Druck in der Aorta und die über Dopplerschall aufge- nommene mittlere Flußgeschwindigkeit (Flow) in der Arteria cerebralis anterior zeigten einen deutlichen Anstieg während der Anfälle. Aus der Kurve des zerebralen Flow wurde der Poucelot-Index als Ausdruck des zerebrovaskulären Widerstands berechnet; dieser Index fiel ab. In Bezug auf den zerebralen Stoffwechsel und den Flow sowie auf die Verbindung zwischen Stoffwechsel und Flow und die Druck-Flow-Autoregulation sind drei sich widersprechende Interpretationen möglich. Disku- 
tiert wird eine Sympathikusaktivierung mit ihren Auswirkungen auf die zerebrale Hämodynamik. Es wird aufgezeigt, daß die Fähigkeit zur Druck-Flow-Autoregulation während Blutdruckveränderungen in Assoziation mit einer geänderten Sympathikusaktivierung nicht zuverlässig untersucht werden kann. Wir stellen ein elektrisches Modell des systemischen arteriellen Schenkels vor, an dem gezeigt werden konnte, daß der „Widerstands- i 1

Index" durch Veränderungen folgender Parameter wahrscheinlich stark beeinflußt wird: zerebroarterielle Weitstellung, peripherer Widerstand, Dauer der Systole als Teil des Herzzyklus und Durchgängigkeit des Ductus arteriosus. Um einige dieser Fehlermöglichkeiten zu vermeiden, sollte ein Pulsations-Index eingeführt werden, der den arteriellen Pulsdruck berücksichtigt.

Schlüsselwörter: Anfall, zerebrale Hämodynamik, Dopplersonographie, hämodynamisches Modell, Neugeborenes, Sympathikusaktivierung.

\section{Résumé}

Analyse des courbes doppler de vélocité sanguine cérébroartérielle chez les enfants nouveaux-nés: vers un index des résistances cérébrovasculaires

On utilise de plus en plus largement l'effet doppler ultrasonore pour étudier l'hémodynamique cérébrale, chez le nouveau-né humain. Ce rapport présente un enregistrement continu, chez un enfant présentant des crises comitiales. La fréquence cardiaque, la pression aortique moyenne et la vélocité sanguine moyenne, étudiée au niveau de l'artère cérébrale antérieure, au doppler ont toutes présenté une augmentation importante au cours des crises. On a calculé l'indice de Pourcelot, sur les courbes de vélocité sanguine cérébrale, cet indice est supposé refléter les résistances cérébrovasculaires. Cet indice diminue. Trois interprétations réciproquement contradictoires sont possibles en termes de rythme méta- bolique cérébral, flux sanguin cérébral, couplage métabolisme/flux sanguin. On discute l'activation sympathique et ses effets sur l'hémodynamique cérébrale. On met en évidence que la capacité d'autorégulation pression/ flux ne peut pas être étudiée de façon fiable, au cours des modifications de la pression artérielle avec activité sympathique perturbée. On présente un modèle électrique du système artériel systémique et on l'utilise pour démontrer que l'indice de résistance est vraisemblablement profondément modifié par les variations de la compliance artérielle cérébrale, des résistances périphériques, de la durée de la systole en tant que fraction du cycle cardiaque et reflet du canal artérial. On suggère un ratio d'indice du pulsatilité, corrigé en fonction de la pression du pulse artériel, afin d'éviter certaines de ces erreurs.

Mots-clés: Activation sympathique, comitialité, doppler, hémodynamique cérébrale, modèle hémodynamique, nouveau-né.

\section{References}

[1] BaDa H, W HaffaI, C ChUa: Non-invasive diagnosis of asphyxia and intraventricular haemorrhage by Doppler ultrasound. J Pediatr 95 (1979) 775

[2] Baton DG, J Hellman: Regional cerebral blood flow, cerebral blood velocity and pulsatility index in newborn dogs. Pediatr Res 17 (1983) 908

[3] Bejar P, TA Meritt, RW Coen, F Manning, L GLUCK: Pulsatility index, patent ductus arteriosus and brain damage. Pediatrics 69 (1982) 818

[4] BOURNE PR, RI KITNEY: Comparison of computer models of the human arterial system for the assesment of clinical data. Med Biol Eng Comput 21 (1983) 319

[5] Drayton MR, PN BuRns: Cerebral blood flow in respiratory distress syndrome - Regional changes observed using duplex doppler ultrasound. Neonatal Society Meeting, London, November 1983

[6] Edvinsson L, ET MAcKenZIE: Amine mechanisms in cerebral circulation. Pharmacol Rev 28 (1977). 275
[7] Greisen G, K Johansen, PH Ellison, PS FreDRIKSEN, J MALI, B FRIIS-HANSEN: Cerebral blood flow in the newborn infant: Comparison of Doppler ultrasound and 133-Xenon clearance. J Pediatr 104 (1984) 411

[8] HaNsen NB, BS Stonestreet, TS Rosenkrantz, W OH: Validity of Doppler measurements of anterior cerebral artery blood flow velocity: Correlation with brain blood flow in piglets. Pediatrics 72 (1983) 526

[9] LOU HC, B FrIS-HANSEN: Arterial blood pressure elevations during motor activity and epileptic seizures in the newborn. Acta Paediatr Scand 68 (1979) 803

[10] LOU HC, NA LASSEN, B FrIIS-HANSEN: Is arterial hypertension crucial for the development of cerebral haemorrhage in premature infants? Lancet $i$ (1979) 1215

[11] LUNDELL BPW, DP LINDSTRøM, TG ARNOLD: Neonatal cerebral blood flow velocity: An in vitro 
validation of the pulsed Doppler technique. Actu Palcediatr Scand (in press)

[12] Piankjman JM, JJ Vol.pe: Seizures in the preterm infant: Liffects on curebral blood flow velocity, intracranial pressure and arterial blood pressurc. J Pediatr 102 (1983) 288

[13] Pourclilor L: Applications cliniques de l'examin Dopplor transcutane. In: Velocimetric ultrasonore Doppler. Inscrm 34 (1974) 213

[14] Risisisk J, P SMitri: Prediction of hemispheric blood llow from carotid velocity meusurements. Stroke 11 (1980) 399

[15] SKIIJM(ORE R, JP WoOJCock: Physiological interpretation of Doppler shift waveforms - 1. Ultrasound Med Biol 6 (1980) 7
[16] Spincer MP, AB Dinison: Pulsutile flow in the vascular system. In: HAMuLTON WF (ed): Handbook of physiology, section 2, p. 844. Am Soc Physiol, Ballimore 1963

[17] Vol.j!! JJ. JM PIIARL,Man, A HIL,. JB MCMiBnamin: Cercbral blood flow velocity. The value of its delerminution. Pediatrics 70 (1982) 147

Received Junuary 7, 1985. Revised June 20, 1985. Accepted July 9. 1985.

Gorm Greiscin, M.D.

Department of Neonatology

Rigshospitulet

Blegdamsvej 9

2100 Copenhagen 0

Denmark 